\title{
Increased Secretion of Müllerian Inhibiting Substance after Immunological Blockade of Endogenous Luteinizing Hormone Releasing Hormone in the Rat*
}

\author{
BARRY B. BERCU, $\dagger$ YASUHIDE MORIKAWA, IVOR M. D. JACKSON, AND \\ PATRICIA K. DONAHOE \\ Department of Pediatrics, Division of Pediatric Surgery, and the Pediatric Surgical Research Laboratory, \\ Massachusetts General Hospital, the Departments of Surgery and Pediatrics, Harvard Medical School, and the \\ Endocrine Division, New England Medical Center, Tufts University School of Medicine, \\ Boston, Massachusetts, USA
}

\section{Summary}

In order to evaluate the role of leuteinizing hormone releasing hormone (LHRH) and gonadotropins in the control of secretion of Müllerian inhibiting substance, groups of pregnant rats were injected intraperitoneally with high potency antiserum from a rabbit immunized with LHRH. Pregnant females were injected at 13 and 20 days of gestation with LHRH antiserum or an

* This research was supported in part by USPHS Grants AM-0703902 and CA17393-02.

† Special Fellow, United States Public Health Service, New England Medical Center, and Research and Clinical Fellow, Massachusetts General Hospital. To whom requests for reprints should be addressed. equal volume of normal rabbit serum as a control. The testes and penis were reduced in weight and size in 6-day-old pups of the experimental group indicating the luteinizing hormone (LH) was blocked and that LHRH antiserum was active. Testicular fragments of 17-day fetuses and 6-day-old pups showed an increase relative to controls in Müllerian inhibiting substance activity in a graded organ culture bioassay system. These studies suggest that secretion of Müllerian inhibiting substance is curtailed by one or both gonadotropins.

\section{Speculation}

The secretion of Müllerian inhibiting substance is under inhibitory gonadotropin control, dependent on normal hypothalamic secretion of LHRH. 
Two hormones govern the embryonfc development of male genitalia. MüllerIan inhibiting substance, first described in mammals by Jost $(15,16)$ causes regression during mid-gestation of the Müllerian ducts of male. fetal development in the rat $(19,20)$. This hormone is secreted by the testis from day 14 of gestation unt11 birth and in progressively lesser concentrations, unt11 21 days after birth (8). The second hormone, testosterone, induces development of the Wolffian duct into the vas deferens, seminal vesicle and epididymis (9): and its active metabolite, 5-dihydrotestosterone, stimulates the urogenital sinus, genital tubercle, genital folds, and genital swellings to form prostate, glans, penis and scrotum (9).

It is not certain whether Mullerian inhibiting substance is autonomous or whether 1t responds to extragonadal hormonal influences. Studies of the pituitary control of mammalian Mullerian inhibiting substance have been inconclusive. Maraud et al, have shown an increase in Müllerian Inhibiting substance activity of the $\frac{2}{2}$ month old chick testes after hypophysectomy at 1 month $(17,18)$. Groenendif-Huifbers and Burggraaff noted a spontaneous. old chick (10). Rats hypophysectomized at 20 days of age falled subsequently to demonstrate. Rats hypophysectomized at 20 days of age falled subsequently to demonstrate testicular Müllerian Inhibiting substance activity (8). Neit
prolactin (Donahoe et al, unpublished) nor placental fragments (8) added to prolactin (Donahoe et al, unpublished) nor placental fragments (8) added to activity.

Previously, we used lutelnizing hormone releasing hormone (LHRH) antiserum to block endogenous LHRH secretion in the neonatal rat $(3,4,5)$. Both serum concentration and pituitary content of follicle stimulating hormone (FSH) serum concentration and pituitary content of follicle stimulating hormone (FS
and luteinizing hormone (LH) were reduced after injection of LHRH antiserum $(2,14)$.

In this study, pregnant rats and their pups were treated with LHRH ant1serum in order to examine whether LHRH and
Müllertan inhibiting substance secretion.

\section{Methods and Materials}

Animals. Adult rats were obtained from Holtzman Laboratories. Females In estrus had been caged with males overnight and those with sperm positive vaginal smears on the following day were kept for study. The animals were housed in a temperature-controlled room with a daily lighting schedule of 14
hours of $11 \mathrm{ght}$ and 10 hours of darkness and had free access to Purins rat chow and tap water.

Bioassay. The presence of Mulllertan inhtbiting substance was assayed by a graded organ culture method (7). The agonadal reproductive ducts from $141 / 2$ day female fetuses were placed on an agar coated stainless steel grid of a Falcon 3010 organ culture dish. One to $2 \mathrm{~mm}$ fragments of testicular tissue to be assayed were placed adjacent to the ducts. Incubations were performed over wells containing $2 \mathrm{ml}$ of media (CMRL $10 \%$ fetal calf serum 200 units penicillin and $200 \mathrm{mcg}$ streptomycin) (Gibco) at $37^{\circ} \mathrm{C}$ for 72 hours in a humidified atmosphere of $95 \%$ air and $5 \% \mathrm{CO}_{2}$. Spectmens were then fixed in buffered formalin, dehydrated in an alcohol series, cleared in xylene, and embedded in paraffin. The cranial end of the duct was cut in serial cross-sections and stained with hematoxylin and eosin. Multiple sections were studied by light of two observations by independent experienced observers was recorded.

\section{LHRH Ant1serum.}

Ant1serum to LHRH was generated in rabbits by repeated intraderma1/subcutaneous infections of synthetic LHRH conjugated to bovine thyroglobulin by bisdiazotized benzidine (Jackson, in preparation). This technique was similar to that used to generate antibodies to thyrotropin releasing hormone (12). For the Initial injection, the complex was emulsified in Freund's complete
adjuvant; subsequent injection utflized incomplete adjuvant. The LHRH ant1adjuvant; subsequent infection utflized incomplete adjuvant. The LHRH ant serum showed no cross-reactivity with deamido-LHRH, thyrotropin releasing
hormone, somatostatin, vasopressin, trilodothyronine, thyroxine, or angiote hormone, somatostatin, vasopressin, trilodothyronine, thyroxine, or angioten-
sin I or II. The antibody reacted with the C-terminal nonapeptide to pentapeptide fragments of LHRH but not significantly with N-terminal fragments.
$1: 280,000$ dilution of LHRH ant1serum bound $45 \%$ of labelled LHRH under the conditions of our LHRH radiofmmunoassay (Jackson et al, in preparation).

\section{Experiment Protocol. Effect of LHRH antiserum on fetal and neonatal male rats}

Thirteen day pregnant females were chosen for injection because LHRH antiserum did not interfere with normal continuation of pregnancy (2)
Müllerlan duct regression had not begun in normal male fetuses (7).

In vitro (Figure 1). Ten 13-day old pregnant rats were given $1 \mathrm{ml}$ of LHRH antiserum intraperitoneally, and another ten rats were treated with an equal volume of normal rabbit serum. At 17 days gestational age, male fetuses were removed from each of 2 experimental and 2 control mothers. One testis from each male fetus was removed and a small fragment placed aseptically on an agar coated stainless steel grid adjacent to the urogental ridge of a $1 / 2$ day female rat embryo for Müllerian inhibiting substance assay. The $1 \mathrm{ml}$ LHRH antiserum or normal rabbit serum on the 20th day of pregnancy. After delivery the males were carefully marked as LHRH antiserum or control pups, then were randomly assigned to either experimental or control mothers in pups, then were randomly assigned to either experimental or control mothers in
equal numbers. At six days of age, 5 experimental and 5 control animals were equal numbers. At six days of age, was weighed and duplicate $1-2$ man $\mathrm{fragments}$ of the other evaluated for Muller
inhibiting substance assay. The penis was also removed and measured under a Nikon dissecting microscope.

Six-day old male pups from a mother treated with LHRH antiserum were given $0.25 \mathrm{ml} \mathrm{LHRH}$ ant Iserum intraperitoneally, and similarly, the remaining equal number of male pups from a mother which had recelved normal rabbit serum were given $0.25 \mathrm{ml}$ normal rabbit serum intraperitoneally. At 10 days of age, the animals were we

In vivo. In order to determine if early changes in Müllerian Inhibition could be elicited in vivo, a sma1ler group of 6 exper pregnant females were infected with one ml of LHRH antiserum or normal rabbit serum on day 13 of gestation. Two experimental and two control mothers were killed on day 14,15 and 16 of gestation and the male pups were removed. One urogental ridge from each of the pups was removed, fixed in buffered for evaluated directly without further in vitro incubation.

\section{Statistical Analysis}

Group comparisons were analyzed with unpaired $t$ tests. All data are presented as mean + standard error $(\mathrm{SE})$.

\section{RESULTS}

Müllerian inhibiting substance activity. Organ culture of testes from 17-day old male fetuses from dams treated with LHRH antiserum at 13 days fetal age vs. $3.8 \pm 0.5, p<0.05$ ) (Figures 2 and 3 ). Similarly, the testes from 6 -day vs. $3.8 \pm 0.5, p<0.05$ ) (Figures 2 and 3 ). Similarly, the testes from 6 -day
old pups from mothers which had recelved LHRH antiserum at fetal ages of 13 and 20 days had increased Mullerian Inhibiting substance activity (Grade 4.7 \pm 0.1 vs $3.6 \pm 0.4, p<0.01$ ). Testes from animals 10 days of age did not
differ between treatment and control groups (Grade $2.8 \pm 0.4$ vs. $2.1 \pm 0.3$ ).

Direct in vivo evaluation of Müllerian duct regression in male fetuses by assessment of the urogenital ridge on gestational days 14,15 and 16 after injection on day 13 , revealed no difference between LHRH antiserum treated and of 14-day fetal testes, and not significantly different in 15-day fetal testes, Grade $2.4 \pm 0.1$ vs. $2.4 \pm 0.2$, and 1 in 16 -day fetal testes, $4.3 \pm 0.2$ vs. 4.0

Testicular Weights and Penis Size. The weight of one testis was reduced in pups from dams injected with LHRH antiserum vs, that from dams given normal rabbit serum (Table 1). Similarly, the penis length was reduced in the same differ, inferring that general health was unaltered.

\section{DISCUSSION}

The antiserum to LHRH used here has been shown previously to act translently and depress serum testosterone LHRH antibody appeared to cross the maternal placental barrier because the male pups of antiserum injected mothers had smaller testes than those of con-
trol dams. Presumably, this was due to inhibition of secretion of one or trol dams. Presumabiy, this was due to inhibition of secretion of one or
both fetal gonadotropins. Furthermore, the testes of pups whose mothers had been injected with the antiserum to LHRH displayed increased secretion of Müllerian inhibiting substance in the organ culture bioassay. These studies suggest that one or both fetal gonadotropins inhibit the secretion of Múllerian inhibiting substance in late fetal and early neonatal life. The gonadotropin more likely to be responsible for this effect is FSH because FSH is known to the sertoli cell is the source of Müllerian inhibiting substance $(6,13)$.

The lack of difference between experimental and control groups in the in vivo examination of the male urogenital ridge at 14-16 days is explicable. Any Increase in the rate of Müllerian duct regression cannot be observed in less than 72 hours, the time 1nterval necessary to visualize microscopically the morphological changes induced by Müllerian inhibiting substance, namely the autodigestion of the tissues $(7,21)$. Thus, one would expect to find no difference at this early time between Mullerian duct regression of the control and the experimental group. The in vitro bioassay results suggest that the content or release of Müllerian inhlbiting substance from the testis is increased in animals whose endogenous serum gonadotropins are reduced. At 10 days of age there was no difference in Müllerlan Inhibiting substance activity In the testes suggesting a loss of sensitivity to gonadotropins, particular1y gonadotropins on Müllertan fnhibiting substance secretion.

Maternal infection of antiserum to LHRH also caused a marked decrease In the size of the penis of male pups. This suggests that the normally low
circulating level of serum testosterone 18 necessary for normal pentle growth.

Th1s study Indicates that normal Müllerian Inhibiting substance secretion is dependent on hypothalamic function through LHRH regulation of gonadotropin release. Whether one or both gonadotropins are important should be studied following the administration of specific antisera to leuteinizing hormone and follicle stimulating hormone.

\section{BIBLIOGRAPHY}

1. Arimura, A. In vivo methods for studying the action of hypothalamic hormones with special reference to their antisera as tools for investigation. In: Labrie, F., Me1tes, J. and Pelletier, G. Hypoth
pp. 387-396 (Plenum Press, New York, 1976).

2. Arimura, A., Shino, M., De La Cruz, K.G., Rennels, E.G., and Schally, A.v.: Ef fect of active and passive immunization with luteinizing hormone releasing hormone and follicle-stimulating hormone levels and the ultrastructure of the
pituitary gonadotrophs in castrated male rats. Endocrinology 99:291 (1976).

3. Bercu, B.B., Jackson, I.M.D., Safali, H., Sawin, C.r., and Reichlin, S. The development of the pituitary gonadal axis in the male rat requires the luteinizing hormone releasing hormone (LRH) decapeptide from birth.
society meeting, San Franclsco, Abstract No. 365, p. 239 (1976).

4. Bercu, B.B., Jackson, I.M.D., Safail, H., and Retchlin, S.: Testicular development requires lutelnizing hormone releasing hormone (LRH) from birth. Evidence from studies of Immunological blockade of endogenous LRH 1n
Vth International Congress of Endocrinology, Hamburg, Germany (1976). 5. Bercu, B.B., Jackson, I.M.D., Safa11, H., and Relchlin, S.: Permanent
impairment of testicular development after transient Immunological blockade
of endogenous LHRH in the neonatal rat. Endocrinology (In press). 6. Blanchard, M.G., and Josso, N.: Source of the anti-Mullerian hormone synthesized by the fetal testis: Mullerian inhibiting activity of fetal
bovine sertoll cells in tissue culture.: Pediat. Res. 8: 968 (1974).

7. Donahoe, P.K., Ito, Y., Hendren, W.H.: A graded organ culture assay for the detection of Mullerian Inhibiting Substance. Journal of Surg. Res. (in press).

8. Donahoe, P.K., Ito, Y., Marfatia, S., and Hendren, W.H., III: The production of Mullerian Inhibiting Substance by the fetal, neonatal and adult rat. Biol. of Reprod. 15:329 (1976).

9. Donahoe, P.K., and Hendren, W.H.: Evaluation of the newborn with ambiguous genttalia. Pediat. C1inics of North America 23:361 (1976).

10. Groenendiflk - Huijbers, M., and Burggraaff, J.: Experimental studies on capability of embryonic and young chicken testes to regress embryonic chick oviducts. Anat. Anz. Bd. 135: 43 (1974).

11. Hansson, V., Ritzen, E.M., French, F.S., and Mayfeh, S.H.: Androgen D.W., and Greep, R., Handbook of Physlology Section 7, Endocrinology Volume 
V, Male reproductive system, pp. 173-201 (American Physiological Society, 1975)

12. Jackson, I.M.D., and Relchlin, S.: Thyrotropin releasing hormone (TR.H): distribution in hypothalamic and extrahypothalamic brain tissue of mammalian and submamnalian chordates. Endocrinology 95:854 (1974).

13. Josso, N.: In vivo synthesis of Mullerian inhibiting hormone by seminiferous tubules isolated from the calf fetal testis. Endocrinology 93:829 (1973).

14. Koch, Y. Chobsieng, P., Zor, U., Fridkir, M. and Lindner, H.: Production and characterization of an antiserum to synthetic gonadotropin releasing hormone. Blochem. Blophys, Res. Comtr. 55: 623 (1973).

15. Jost, A.: Sur 1a differentiation sexuelle de l'embryons de lapin remarque au sujet de certaines operations chirugical. C.R. Biol. 140:460 (1946).

16. Jost, A.: Sur les derives mullertens de 1 'embryons de lapin des deux sexes castres a 21 jours. C.R. Soc. Biol. 141:135 (1947).

17. Maraud, R., Couland, H., and Stoll, R.: Role inhibiteur de 1'hypophyse sur $1^{\prime}$ elaboration de 1 'inducteur testiculaire responsible de la regression

18. Maraud, R., Stoll, R., and Couland, H.: Donnes nouvelles sur les role du testicule et de 1 'hypophyse dans la differenciation sexualle du poulet. C.R. Soc. Biol. 55:442 (1970).

19. Picon, R.: Action due testicule foetal sur le development in vitro des canaux de Muller 1e rat. Arch Anat. Micro. Exp. 58:1 (1969).

20. Picon, R.: Modification in the course of testicle development and its inhibitory action on the Mullerian ducts in vitro. C.R. Acad. Sc1. 21:2370 (1970).

21. Price, J.M., Donahoe, P.K., Ito, Y., Hendren, W.H.: Programmed cell death in the Mullerian duct Induced by Mullerian Inhibiting Substance, Amer. J. Anat., (in press).

22. Received for publication May 11, 1977.

23. Accepted for publication September 21, 1977.

\section{ACKNOWLEDGEMENTS}

The authors thank Drs. Seymour Reichlin, Jack Crawford, Ineze Beitins, and Fabrizio Michelassi for their helpful suggestions. We also thank Mr. Carmelo Bond1 and Thomas Manganaro for technical assistance and Ms. B.J. Cap1stran, Ms. Margaret Doherty and Mrs. Penny Colbert for secretarial assistance.

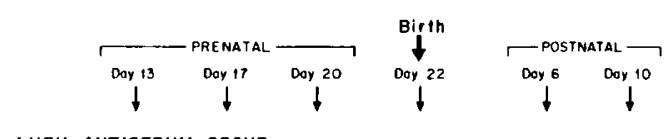

LHRH ANTISERUM GROUP

$$
\text { LHRH-AS }
$$

$$
\text { NORMAL RABBIT SERUM GROUP }
$$

Figure 1

Schematic representation of experimental protocol. Luteinizing hormone releasing hormone ant (serum (LHRH-AS) or normal rabbit serum (NRS) were releasis hormal rabblt serum (NRS) were 1n 6 ens Mü 6 days postnatal life. Croups of rat pups at 6 and 10 days postnatal $1 \mathrm{ffe}$.

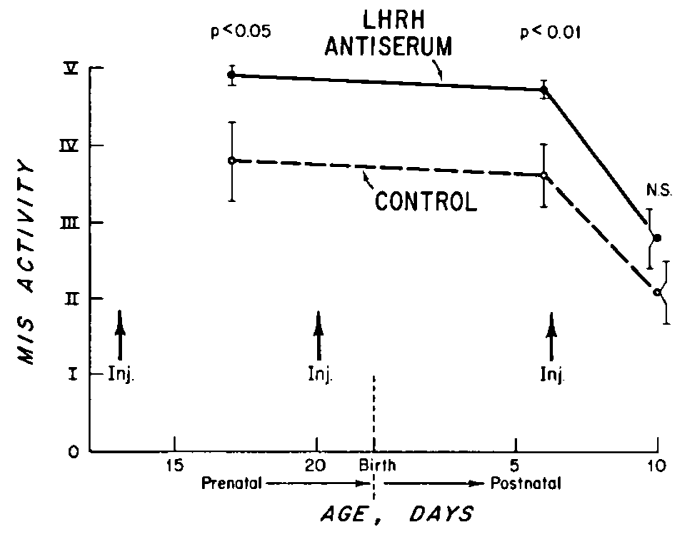

Figure 2

Müllerian inhibiting substance activity of testes of fetuses of dams treated with elther luteinizing hormone releasing hormone (LHRH) antiserum or normal rabbit serum. The means $\pm S E$ of the graded organ culture assay are compared in 17-day fetuses, 6 and 10-day old rats.

\begin{tabular}{|c|c|c|c|}
\hline Ireatment & Test is weight (mg) & Pen1s length $(\mathrm{mm})$ & Body wei ght (g) \\
\hline \multicolumn{4}{|l|}{6 days old: } \\
\hline LHRH-AS & $5.8 \pm 0.3 *$ & $5.69 \pm 0.17 \star \star \star$ & $10.1 \pm 0.3$ \\
\hline NRS & $7.0 \pm 0.3$ & $6.50 \pm 0.16$ & $10.0 \pm 0.4$ \\
\hline \multicolumn{4}{|c|}{10 days old: } \\
\hline $\begin{array}{l}\text { LHRH-AS } \\
\text { NRS }\end{array}$ & $\begin{array}{r}7.9 \pm 0.3 \\
10.9 \pm 0.7\end{array}$ ** & $\begin{array}{l}5.93 \pm 0.07 \\
6.84 \pm 0.05\end{array}$ \#** & $\begin{array}{l}111.9 \pm 0.4 \\
11.4 \pm 0.4\end{array}$ \\
\hline
\end{tabular}

Table 1. Testis welght, penis length, and body welght in rats born to dams treated with luteinizing hormone releasing hormone antiserum (LHRH-AS) or notmal rabbit serum (NRS) 


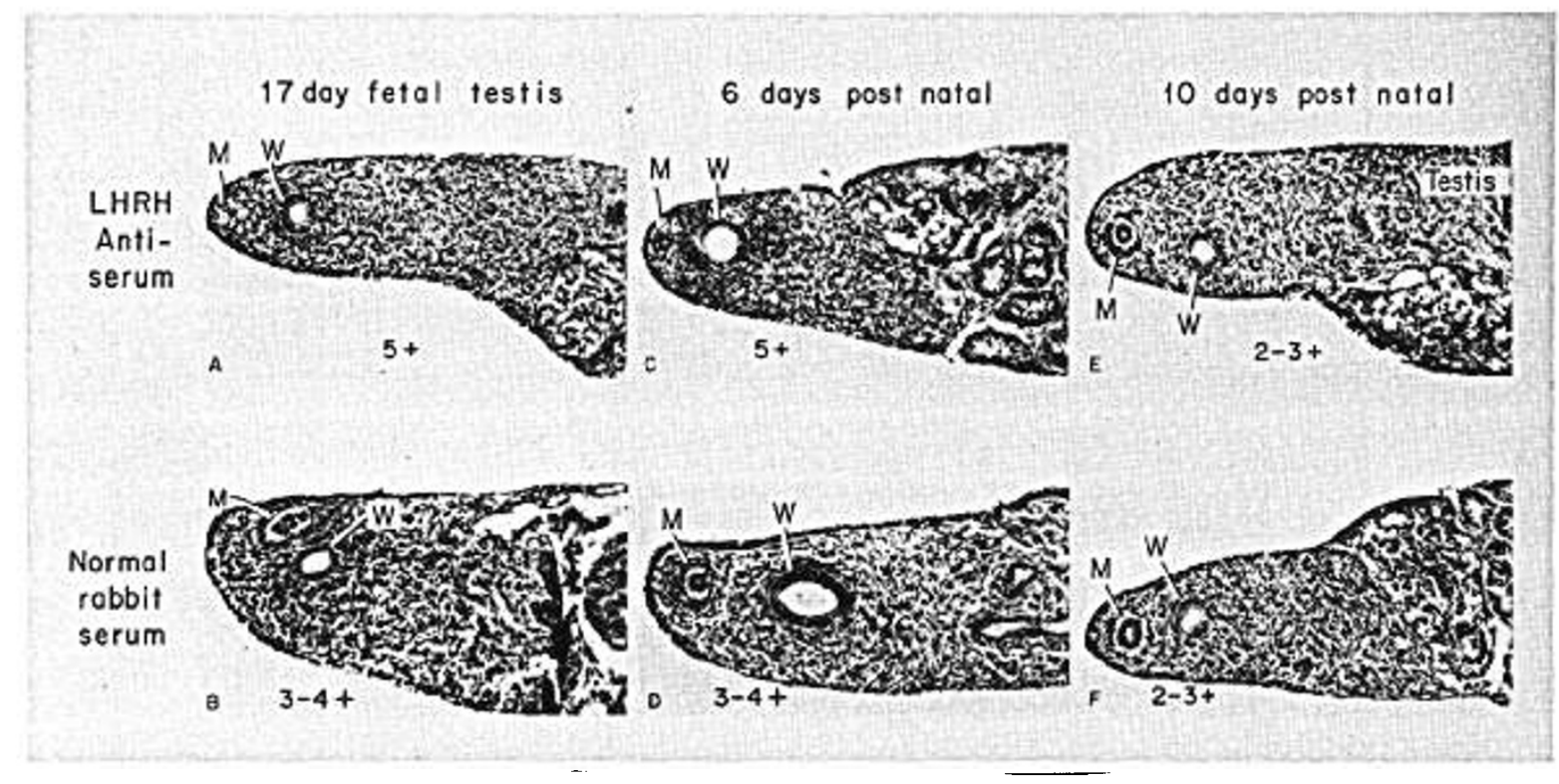

Figure 3

Müllerian duct regression caused by testes from 17-day fetuses and 6-day of male rats born to dams treated with luteinizing hormone releasing

$0031-3948 / 78 / 0012-0139 \$ 02.00 / 0$

Copyright $\mathcal{C} 1978$ International Pediatric Research foundation, Inc. hormone (LHRH) antiserum or normal rabbit serum. Arrow points to Müllerian

Printed in U.S.A. 